\title{
MEDIAÇÃO DE CONFLITOS: DILEMAS E DESAFIOS À DESCENTRALIZAÇÃO DAS ESTRUTURAS JURISDICIONAIS NO CONTEXTO DO MOVIMENTO DE ACESSO À JUSTIÇA NO BRASIL
}

\section{CONFLICT MEDIATION: DILEMMS AND CHALLENGES TO DECENTRALIZING JURISDICTIONAL STRUCTURES IN THE CONTEXT OF THE MOVEMENT OF ACCESS TO JUSTICE IN BRAZIL}

Fabiana Alves Mascarenhas*

\begin{abstract}
Resumo: O presente artigo incita uma discussão sobre a mediação como ferramenta de solução de conflitos, especialmente na seara familiar, abordando os desafios impostos ao instituto pela cultura existente a partir da ideia de Estadania. Lança-se um olhar sobre a necessidade de, no atual momento de crise da Justiça, consequência da própria crise do Estado, priorizar um método mais humanístico que garanta, com maior qualidade, a obtenção da Justiça, em sua ampla acepção. A hipótese é de que torna-se essencial estimular este agir comunicativo em uma sociedade marcada pelo individualismo, pelo conflito, pela relação adversarial e competitiva. Sugere-se o deslocamento da ênfase da solução do conflito do Poder Judiciário brasileiro para os próprios sujeitos da relação, tendo como marcos teóricos a cultura da pacificação social com justiça, a democracia constitucional-deliberativa e o princípio da intervenção mínima do Estado e da máxima cooperação entre as partes. Tornar a Justiça atingível aos cidadãos é a melhor maneira de fazer com que a mesma seja valorizada e perseguida pelos mesmos, consolidando um verdadeiro Estado Democrático de Direito.
\end{abstract}

Palavras-Chave: Acesso à Justiça. Mediação de Conflitos. Crise do Judiciário.

Abstract: The following paper encourages a discussion of the institute of mediation as a tool to resolving conflicts, especially in the family area, addressing the difficulties of the institute because of the culture rooted from the idea of Estadania. A glance is launched at the necessity of, at the present moment of crisis at Judiciary, result of the own crisis of the state, prioritize a more humanistic method that guarantees, with higher quality, the attainment of Justice. The hypothesis is that becomes essential to stimulate this communicative action in a society marked by individualism, by the conflict, by the adversarial and competitive relationship, in other words, the predominance of the instrumental action. It is suggested to dislocate the emphasis of the process solutions for its own subjects, taking as theoretical frameworks the culture of peace, a deliberative-constitutional democracy, and the principle of minimum intervention of the state and maximum cooperation between the parties. Make the ideal of Justice attainable for citizens is the better way of making it prized and pursued by them, consolidating a true democratic state.

Key Words: Access to Justice. Mediation of Conflicts. Crisis at Judiciary.

\footnotetext{
* Doutorado e Mestrado em Ciências Jurídicas e Sociais pela Universidade Federal do Estado do Rio de Janeiro (UNIRIO). Professora de Direito Processual do Centro de Ensino Superior de Valença (UNIFAA) e da Faculdade Vértice (UNIVERTIX). E-mail: famascarenhas@live.com.
} 


\section{INTRODUÇÃO}

Subsiste-se um contexto existencial delicado, com a eclosão de uma globalização desenfreada, onde barreiras geográficas são suprimidas devido à velocidade com que os dados circulam, tendências são disseminadas à razão de segundos, a informação por vezes se torna mais poderosa que os bens materiais e o poder político é por vezes utilizado beirando o totalitarismo.

Neste enredo, entre as tensões dialéticas da modernidade ocidental, e da crise que as atravessa, sobra pouco espaço para a valorização do material humano, e coloca-se o problema de saber como tornar os direitos humanos um recurso político ao mesmo tempo cultural e global, efetivando a inclusão do outro, dirimindo as diferenças e instituindo o diálogo como instrumento de emancipação social.

Graças ao exposto, a vida em sociedade tem se tornado mais complexa e as relações humanas mais latentes, logo, os dissensos são acentuados, e o aparato estatal não encontra vazão para garantir, com eficiência, a pacificação social.

O movimento de Acesso à Justiça refletiu-se de maneira peculiar em nossas fronteiras, e é baseado neste pano de fundo que o artigo pretende justificar a consolidação do uso dos métodos adequados de solução de conflitos, neste caso específico, a mediação, prática regulamentada no ordenamento jurídico brasileiro que nutre grande potencial na construção de uma sociedade mais consciente e hábil a perseguir o ideal de seus direitos.

Será feita uma abordagem, dentro da atual crise no sistema Judiciário, dos benefícios da mediação e suas características, especialmente na seara dos conflitos de família, tomando o conceito de "agir comunicativo", de Habermas, como legitimador de uma relação entre sujeitos iguais no diálogo, no sentido da construção de um espaço público democrático.

Traça-se um perfil sobre as características e o perfil do profissional de mediação, para que seja ele o meio eficaz de desconstrução de conflitos e construção de oportunidades de consenso e, consequentemente, ferramenta de pacificação social. 
Precisa-se acreditar que o diálogo consiste no instrumento eficaz para garantir a prática da cidadania, tornando os ideais da Justiça verdadeiramente acessíveis aos cidadãos.

\section{MOVIMENTO DE ACESSO À JUSTIÇA}

Observa-se um momento de aguda crise em nosso sistema Judiciário. Há uma efetiva sobrecarga de demandas frente ao número de juízes e auxiliares, além de se contar com um processo muito complexo, que de tão formal acaba se distanciando do cidadão comum (CAPPELLETTI; GARTH, 2002, p. 156). As decisões "por atacado", muito mais amparadas na jurisprudência do que na análise dos casos em concreto, juntamente à morosidade da Justiça têm como consequências a perda da efetividade das decisões jurídicas, a impunidade, a sensação de injustiça e a descrença gradativa nas instituições jurídicas como promotoras de estabilidade social, requisitos estes que obstam o exercício efetivo da democracia, uma vez que o garantidor da realização dos direitos individuais é o Estado, por meio do próprio Judiciário.

Este é o ponto de partida para entender a aclamada crise da jurisdição a partir da crise do próprio Estado, onde incapaz de impor uma regulação social, e aprisionado entre um nível internacional mais proativo e um nível infranacional que procura libertar-se de sua tutela, este se encontra em uma crise de legitimidade. (ROTH, 1996).

E é neste cenário que surge a necessidade de uma reestruturação do acesso à Justiça. Segundo Luiz Guilherme Marinoni:

(...) acesso à justiça quer dizer "acesso a um processo justo, a garantia de acesso a uma justiça imparcial, que não só possibilite a participação efetiva e adequada das partes no processo jurisdicional, mas que também permita a efetividade da tutela dos direitos, consideradas as diferentes posições sociais e as específicas situações de direito substancial. Acesso à justiça significa, ainda, acesso à manifestação e à orientação jurídicas e a todos os meios alternativos de composição de conflitos. (MARINONI, 2000, p. 28).

O tema do Acesso à Justiça é um debate que converge diretamente para as questões que relacionam o processo, em seu aspecto formal, com a justiça social, e 
consiste de um dos pontos centrais da moderna processualística, pressupondo um alargamento e aprofundamento de seus objetivos e métodos.

Cappelletti e Garth delinearam o desenvolvimento e surgimento de uma nova e compreensiva abordagem dos problemas que esse acesso significa nas sociedades contemporâneas, originando-se, talvez, da ruptura da crença tradicional na confiabilidade das instituições jurídicas, e inspirando-se no desejo de tornar efetivos, e não meramente simbólicos, os direitos do cidadão comum:

(...) $O$ recente despertar de interesse em torno do acesso efetivo à justiça levou a três posições básicas, pelo menos nos países do mundo Ocidental. Tendo início em 1965, estes posicionamentos emergiram mais ou menos em sequência cronológica. Podemos afirmar que a primeira solução para o acesso - a primeira "onda" desse movimento novo - foi a assistência judiciária; a segunda dizia respeito às reformas tendentes a proporcionar representação jurídica para os interesses "difusos", especialmente nas áreas da proteção ambiental e do consumidor; e o terceiro - e mais recente - é o que nos propomos a chamar simplesmente "enfoque de acesso à justiça" porque inclui os posicionamentos anteriores, mas vai muito além deles, representando, dessa forma, uma tentativa de atacar as barreiras ao acesso de modo mais articulado e compreensivo. (...) Essa "terceira onda" de reforma inclui a advocacia, judicial ou extrajudicial, seja por meio de advogados particulares ou públicos, mas vai além. Ela centra sua atenção no conjunto geral de instituições e mecanismos, pessoas e procedimentos utilizados para processar e prevenir disputas nas sociedades modernas. Nós o denominamos "o enfoque do acesso à justiça" por sua abrangência. Seu método não consiste em abandonar as técnicas das duas primeiras ondas de reforma, mas em tratá-las como apenas algumas de uma série de possibilidades para melhorar o acesso. (CAPPELLETTI; GARTH, 2002, p. 31 e 67-68).

Daí concluírem, Cappelletti e Garth, que no que se refere ao mundo Ocidental, a questão do acesso à Justiça conheceu uma sequencia de três grandes movimentos, que impulsionaram, sem discriminação, tanto os países da civil law como os da common law, a partir de 1960.

Batizado a partir da metáfora das três "ondas", o "access to justice movement ${ }^{\prime \prime}$ teve como primeiro foco da pretendida democratização o incentivo às

\footnotetext{
${ }^{1}$ No plano acadêmico, tal movimento justificou o Florence Project, coordenado por Mauro Cappelletti e Bryant Garth, conjuntamente com o Conselho Nacional de Pesquisa da Itália, e patrocinado pela Ford Foundation (1978). Contando com 23 países, onde grandes juristas montaram um relatório e responderam a questionários, tal projeto consistiu de grande estímulo à academia internacional no sentido da implantação de novos mecanismos de acesso ao Poder Judiciário, e discussão de possíveis soluções técnicas para os problemas de seus sistemas jurídicos, promovendo um enorme intercâmbio de experiências e grande base para os movimentos reformistas que se seguiram. Tal projeto não contou com referências brasileiras sobre o tema, enquanto outros países da América Latina, como Chile, Colômbia, México e Uruguai, se fizeram representar.
} 
iniciativas que visassem uma assistência judiciária a litigantes de baixa renda, sem condições de prover um advogado, essencial em um universo de leis e procedimentos complexos, no intento de ajuizar uma causa.

Em um segundo momento, o movimento convergiu na necessidade de se superar a concepção individualista do processo, visto apenas como interesse de duas partes, introduzindo reformas que permitissem um novo panorama sobre os denominados direitos difusos, interesses coletivos ou grupais que vinculam importantes assuntos de política pública². Tal fenômeno, associado à determinada falência do sistema welfareano de proteção social, impulsionou a consciência de que o governo não conseguiria, sozinho, garantir e preservar a defesa dos interesses públicos.

Sobre este novo cenário, atestam Luiz Werneck Vianna, Maria Alice Carvalho, Manuel Melo e Marcelo Burgos:

(...) Pode-se dizer que as novas circunstâncias históricas vividas a partir dos anos 1970, e que, entre outras características, se notabilizaram por desestruturar os mecanismos pelos quais a política welfareana afirmava o primado do bem-comum sobre a fragmentação mercantil, trouxeram à tona não apenas um vasto continente de atores e de direitos ainda não contemplados por políticas públicas, como também uma profunda deslegitimação das instituições governamentais para o desempenho eficaz de tais políticas. É nesse contexto que os sistemas jurídicos terão seu conteúdo simbólico ampliado, sendo convocados a exercer a posição independente de um "advogado do povo" contra o establishment ou contra o próprio Estado, na defesa de interesses não representados dos consumidores, do meio ambiente, dos idosos, das crianças, entre outros. (VIANNA et al., 1999, p. 159).

A terceira e última "onda", finalmente, foca no reconhecimento da importância das reformas anteriores, mas tem um alcance muito mais amplo, no sentido de tornar efetivas referidas propostas. O caminho parte no intento de promover alternativas e reformas nos tribunais, buscando economia de tempo e dinheiro, além de uma adequação procedimental no tratamento de determinadas demandas, em que os tribunais fazem parte de um conjunto integrado de meios de resolução de conflitos, fomentando a ampliação dos laços entre o Judiciário e a

\footnotetext{
2 Na obra de M. Cappelletti e B. Garth, os direitos públicos são tratados com pouca diferenciação em relação aos chamados direitos difusos, sendo ambos caracterizados como aqueles que, embora vitais a determinados grupos, não propiciam a fácil organização de seus reclamantes e, por isso, tendem a não ser representados.
} 
população, e expondo o tecido social à intervenção do direito, seus procedimentos e instituições (FUX; BATISTA, 1999, p. 9).

A questão é que este movimento, apesar de ter atingido a realidade ocidental como um todo, refletiu-se de maneira diversa entre os países desenvolvidos e aqueles ainda em desenvolvimento, como é o caso do Brasil, que, partindo da sequencia trina proposta, teria atingido a terceira grande onda de democratização do acesso à Justiça sem que conhecesse uma real eficácia em sua assistência judiciária, e sem grandes avanços no tocante à proteção dos direitos difusos. Neste sentido, dentro do movimento mundial para o estabelecimento de uma justiça coexistencial, baseada na conciliação, em critérios de igualdade social distributiva e na participação da comunidade diretamente interessada na questão controversa, a peculiaridade da experiência brasileira reside no fato de ter sido concebida em um movimento de auto reforma do Judiciário, sem qualquer mobilização por parte da sociedade e sequer dos seus setores organizados na luta pela democratização do país, e em um momento histórico onde as organizações populares se encontravam sob os efeitos negativos do longo período de vigência do regime militar (VIANNA et al., 1999, p. 159).

Outro ponto a ser levantado reside, ao contrário da expectativa de Marshall (MARSHALL, 1967), no fato de que a construção de direitos civis, no Brasil, deveria pressupor a prévia conquista de direitos sociais. A partir dessa constatação, temos a paradoxal realidade em que a população brasileira consegue absorver os direitos ditos do século XX, ou seja, os sociais e coletivos, porém carece de conscientização a respeito de seus direitos individuais.

Logo, de acordo com a análise de Eliane Junqueira, a questão emergente, por volta de 1980, época em que o interesse brasileiro foi despertado para a temática da ampliação do acesso à Justiça, não deve ser procurada na essência do movimento, mas sim no processo de abertura política e social que se iniciava. Diferente do que acontecia em outros países, a principal preocupação nacional não era a ampliação do welfare state, além da expansão dos direitos alcançados por minorias étnicas e sexuais, mas sim a necessidade de se levar à população um conjunto de direitos básicos até então inacessíveis, fruto da marginalização sócioeconômica das populações carentes, da exclusão político-jurídica decorrente do 
regime pós 1964, como também em função da tradição liberal-individualista do ordenamento jurídico brasileiro (JUNQUEIRA, 1996, p. 389-390).

Este caminho percorrido às avessas, proveniente da passagem de regimes ora autoritários para regimes democráticos, que se resume na dificuldade de materialização de um extenso rol de novos direitos constitucionalizados, cuja efetivação dependeria de políticas públicas e sociais consistentes, abre espaço para um inchaço na litigação, com o Judiciário atuando como alternativa para alcançar direitos. O cidadão vai buscar, através do Judiciário, algo que deveria ter sido proposto espontaneamente, através da Administração Pública. Tal litigação, então, está conectada não somente à cultura jurídica e política de determinado país, mas também com o grau de efetividade de concretização dos direitos em determinada população, além da existência de uma estrutura administrativa que respalde tal concretização.

Segundo Boaventura de Souza Santos:

(...) Ao abandonar o low profile institucional, o judiciário assume-se como poder político, colocando-se em confronto com os outros poderes do Estado, em especial com o executivo. Esta proeminência e, consequentemente, 0 confronto com a classe política e com outros órgãos de poder soberano manifestaram-se sobretudo em três campos: no garantismo de direitos, no controle da legalidade e dos abusos do poder e na judicialização da política. (SANTOS, 2011, p. 22).

Tal judicialização da política, tendência de transferência de poder decisório do Poder Executivo e Poder Legislativo para o Judiciário, perpassa todo o discurso jurídico do pós guerra e início do século XXI. Nas palavras de Garapon, explicitando e criticando tal fenômeno:

(...) O espaço simbólico da democracia emigra silenciosamente do Estado para a Justiça. Em um sistema provedor, o Estado é todo-poderoso pode tudo preencher, corrigir, tudo suprir. Por isso, diante de suas falhas, a esperança se volta para a justiça. (...) O sucesso é inversamente proporcional ao descrédito que afeta as instituições políticas clássicas, causado pela crise de desinteresse e pela perda do espírito público. A posição de um terceiro imparcial compensa o déficit democrático de uma decisão política agora voltada para a gestão e fornece à sociedade a referência simbólica que a representação nacional the oferece cada vez menos. O juiz é chamado a socorrer uma democracia na qual um legislativo e um executivo enfraquecidos, obcecados por fracassos eleitorais contínuos, ocupados apenas com questões de curto prazo, reféns do receio e seduzidos pela mídia, esforçam-se em governar, no dia-a-dia, indiferentes e exigentes, preocupados com suas vidas particulares, mas esperando do político aquilo 
que ele não sabe dar: uma moral, um grande projeto. (...) É, portanto, aí, na evolução do imaginário democrático, que se devem buscar as raízes profundas da ascensão do juiz. (GARAPON, 2001, p. 47-48).

\section{DILEMAS ATUAIS DO JUDICIÁRIO}

Muitas questões podem ser colocadas quando o assunto em pauta aborda as dificuldades do sistema Judiciário brasileiro, principalmente na seara procedimental, pois as transformações sofridas pelos tribunais ao longo do tempo lhes confere uma posição oscilante e ambígua.

Uma vez que o novo modelo de desenvolvimento se assenta nas regras do mercado e dos contratos privados, a estabilidade pretendida passa a depender de um sistema Judiciário eficaz, rápido e independente. Tal fato somado à explosão de litigiosidade proveniente do novo marco constitucional e da redemocratização, leva a um grande dilema, o da qualidade e quantidade no que toca ao desempenho dos tribunais.

Grande parte do problema está calcado no paradigma reformista denominado Estado-empresário, que obriga a Administração Pública a responder a critérios de eficiência, eficácia, criatividade, metas, competitividade, parâmetros até então próprios do universo empresarial.

A adequação dos procedimentos jurisdicionais a fim de que qualquer sujeito de direitos obtenha uma resposta do Estado justa e efetiva, realizada no menor tempo possível, tem suscitado debates em todas as esferas da sociedade civil organizada, como atestam Mauro Cappelletti e Bryant Garth:

(...) Em muitos países, as partes que buscam uma solução judicial precisam esperar dois ou três anos, ou mais, por uma decisão exequível. Os efeitos dessa delonga, especialmente se considerados os índices de inflação, podem ser devastadores. Ela aumenta os custos para as partes e pressiona os economicamente fracos a abandonar suas causas, ou a aceitar acordos por valores muito inferiores àqueles a que teriam direito. (...) A Justiça que não cumpre suas funções dentro de um prazo razoável é, para muitas pessoas, uma Justiça inacessível. (CAPPELLETTI; GARTH, 2002, p. 20-21).

Ainda nesta esteira, corrobora Luiz Otávio Linhares Renault:

(...) não se pode mais conceber uma possível efetividade do direito material sem a efetividade do direito processual. Não se tolera mais a ineficácia do direito material, pela falta de resultado do processo. $O$ direito material não 
pode se frustrar no bojo do processo. Se o tempo sempre invadiu a vida do homem, agora ele invade também a vida do processo e exige uma resposta efetiva, que não seja a demora. (RENAULT, 2003, p. 273).

Porém, há que se ter cautela, pois uma vez que a morosidade ${ }^{3}$ se torna um problema estrutural, a desconfiança generaliza-se, influenciando as percepções sociais acerca da Justiça. Por outro lado, não se deve associar ganhos de celeridade com maior eficácia ou maior qualidade no funcionamento dos tribunais. É importante ter em mente que uma justiça rápida não é o sinônimo de uma boa justiça, portanto, esta não deve tornar-se um fim em si mesmo (SANTOS, 2011, p. 44).

O ponto é que não há como desafogar o Judiciário por atos administrativos, de gestão ou de disponibilidade de verbas. É preciso admitir que se faz necessária uma substancial mudança de mentalidade acerca desta realidade, definida como consciência de que os problemas são todos ligados numa rede subjacente global, e por isso, de maneira alguma constituem fatos isolados autônomos (BARBOSA, 2004, p. 387).

Tal mudança de mentalidade encontra sua primeira barreira no próprio ensino jurídico, com a cultura adversarial que de certo modo impregna os profissionais do Direito ainda durante sua formação, nas escolas, universidades, cursos jurídicos, dentre outros. Essa postura, proveniente de uma educação jurídica clássica e obsoleta, calcada na pura falta de informação, mostra-se em total desacordo. Segundo Maria de Nazareth Serpa, sobre a mentalidade do advogado brasileiro:

(...) O mapa psicológico do advogado, que Riskin descreve, é aquele utilizado pela maioria dos profissionais do Direito, e que é apresentado e instruído nas Faculdades. O que aparece, nesses mapas, é determinado pelo poder de duas presunções sobre matérias, que os advogados sustentam:

- Disputantes são adversários, se um ganha, o outro tem que perder.

- Disputas tem que ser resolvidas através do emprego de uma terceira parte, baseado em alguma disposição legal. Ao que se pode acrescentar uma terceira, quarta e quinta presunção:

- Disputas envolvem somente questões legais.

\footnotetext{
${ }^{3}$ Segundo Boaventura de Sousa Santos, a morosidade pode ainda ser identificada como sistêmica ou ativa. Morosidade sistêmica é aquela que decorre da sobrecarga de trabalho, do excesso, da burocracia, positivismo e legalismo. Muitas das reformas processuais e de produtividade no Brasil são importantes para o combate à morosidade sistêmica. Já as situações de morosidade ativa são aquelas situações de processos "na gaveta", de intencional não decisão em que, em decorrência do conflito de interesses em que estão envolvidos, é natural que os envolvidos e os responsáveis por encaminhar uma decisão utilizem de todas as desculpas protelatórias possíveis.
} 
- Advogados somente podem ter em mente os direitos de seu cliente, e estes são incompatíveis com os direitos da outra parte.

- Só existe uma verdade jurídica, e esta só tem uma face.

Estas presunções chocam-se, diametralmente, com as presunções existentes na mediação:

- Disputas envolvem questões psicológicas, sociais e legais.

- Disputantes nem sempre são adversários, e podem ter interesses comuns, ou interesses que se combinam entre si sem determinar um ganhador e um perdedor, e oferecer vantagens para ambos.

- Raramente uma norma genérica e abstrata pode comportar as contingências únicas de um caso concreto, e que ninguém melhor do que as próprias partes conhecem o caso e ninguém melhor do que elas podem regular a respeito. (SERPA, 1999, p. 304-305).

Gladston Mamede, referindo-se ao art. 2, parágrafo único, VI, do Código de Ética e Disciplina da Ordem dos Advogados do Brasil, que estabelece ser um dever dos advogados "estimular a conciliação entre os litigantes, prevenindo, sempre que possível, a instauração de litígios", afirma que:

(...) Percebe a norma, indubitavelmente, que a demanda é um mal, por vezes necessário, mas que, sempre que possível deve ser evitado e que a sociedade, assim como seus membros, lucram mais quando é possível compor os litígios do que quando arrastam longas pendengas judiciárias, nas quais se gasta tempo, dinheiro, para não falar em bens de natureza pessoal (fadiga, ansiedade, estresse, etc.). ... É de boa política discutir os interesses do cliente, expor-Ihe possibilidades, riscos, oportunidades, etc. 0 advogado não é contratado para litigar, mas para resolver o problema do cliente e, para tanto, o litígio nem sempre é a melhor solução. (MAMEDE, 1999, p. 246-247).

Além do apego à cultura adversarial, o paradigma jurídico-dogmático que domina o ensino nas faculdades de direito não consegue se libertar das raízes históricas de sua cultura técnico-burocrática. Segundo Boaventura de Sousa Santos:

(...) Com a tentativa de eliminação de qualquer elemento extranormativo, as faculdades de direito acabam criando uma cultura de extrema indiferença ou exterioridade do direito diante das mudanças experimentadas pela sociedade. Enquanto locais de circulação de postulados da dogmática jurídica, têm estado distantes das preocupações sociais e têm servido, em regra, para a formação de profissionais sem um maior comprometimento com os problemas sociais. (SANTOS, 2011, p. 87).

A questão que fica sem resposta é por que as escolas de direito, em geral, não conseguem romper esse modelo. Pode-se creditar uma parcela de culpa à passividade dos professores, que em sua maioria são selecionados em razão de sua prática profissional, sem qualquer preparação pedagógica ou interdisciplinar, às 
razões de mercado, que regem a implementação de instituições centradas em uma prática pedagógica tecnicista, às barreiras institucionais, ou mesmo ao desinteresse dos alunos, que por vezes buscam a graduação como mera suplementação de carreira, ou requisito para o ingresso em concursos públicos.

Neste sentido, tal ensino não se difere do praticado nas escolas de recrutamento e formação, onde os erros são repetidos e aprofundados, reforçando a criação de um retrato do magistrado brasileiro:

(...) Domina uma cultura normativista, técnico-burocrática, assente em três ideias: a autonomia do direito, a ideia de que o direito é um fenômeno totalmente diferente de todo o resto que ocorre na sociedade e é autônomo em relação a essa sociedade; uma concepção restritiva do que é esse direito ou do que são os autos aos quais o direito se aplica; e uma concepção burocrática ou administrativa dos processos. (SANTOS, 2011, p. 83).

A mentalidade técnico-burocrática dos profissionais, agravada com a excessiva carga de trabalho dos tribunais, forjou a chamada cultura da sentença, definida por Kazuo Watanabe, onde "os juízes preferem proferir sentença ao invés de tentar conciliar as partes para a obtenção da solução amigável dos conflitos. Sentenciar, em muitos casos é mais fácil e mais cômodo do que pacificar os litigantes e obter, por via de consequência, a solução de conflitos". (WATANABE, 2007, p. 7).

Diante de todo este contexto, nos dias atuais, não há como se falar em acesso à Justiça (CAPPELLETTI; GARTH, 2002, p. 8) sem vislumbrar a utilização dos métodos adequados de solução de conflitos, dentro e fora do contexto judicial, visando assegurar e garantir a aplicação dos direitos ameaçados em questão, uma vez que cada vez mais o Judiciário vem sendo atravessado pelas justiças emergentes, nos âmbitos nacionais e internacionais, representadas por formas extra oficiais de tratamento das demandas. Não significa negar a prestação jurisdicional por parte do Estado, mas propor alternativas porventura até menos onerosas e mais rápidas para a satisfação das controvérsias, com métodos mais humanísticos, que garantam, com maior qualidade, a obtenção da Justiça. 


\section{DESCENTRALIZAÇÃO DAS ESTRUTURAS JURISDICIONAIS: A PROPOSTA DOS MEIOS ADEQUADOS DE SOLUÇÃO DE CONFLITOS}

Segundo a dinâmica sociológica e política, será possível concluir que, na atualidade, cabe somente ao Estado, através do poder Judiciário, a prerrogativa de dizer o Direito? Seria a Jurisdição monopólio do Estado? A inquietação no que se refere a tais perguntas, e suas possíveis respostas, se tornaram recorrentes frente à tendência mundial de desjudicialização dos conflitos.

É possível afirmar que a vida social gera suas próprias relações. Assim sendo, o Poder Judiciário brasileiro não se encontra preparado, hoje, para lidar com a multifacetada lógica da economia e da vida globalizadas. Nesta perspectiva, o tempo do processo judicial não se coaduna com o do mercado, tempo este da simultaneidade. Logo, abrem-se as brechas para a necessidade de implementação de procedimentos jurisdicionais alternativos, ditos adequados, como a conciliação, negociação, arbitragem e a mediação, visando alcançar rapidez, informalização e pragmaticidade.

Porém, há a tendência cultural, na explicação de José Murilo de Carvalho, de confundir cidadania com estadania. (CARVALHO, 2002). Nesta, a sociedade se molda a partir da vontade do Estado, em profundo contraste com a verdadeira essência do termo cidadania. Como reflexo, temos a postura instalada em nossa sociedade civil organizada de que cabe somente ao Estado, através do Judiciário, a solução dos conflitos. (MORAIS, 2003, p. 80).

A sociedade aprendeu a levar os conflitos para os tribunais. Com as leis aprendeu a evitar a violência, a guerra e a cobrança de seus interesses, necessidades e direitos, com as próprias mãos. Mas se esqueceu de como resolver conflitos em meio a estas mesmas necessidades e interesses, delegando poderes que só ela por si pode exercer. Esqueceu-se de como conquistar e administrar a paz. (SERPA, 1999, p. 62).

Ainda sobre o tema, discorre César Fiuza:

(...) A cultura brasileira transformou e Estado em pai e mãe de todos. Dele dependemos para tudo. Ele é o grande culpado por todos nossos males e, também, o único benfeitor. Sintetiza o Estado brasileiro as figuras do bandido, do mocinho, do bode expiatório e do salvador da pátria. Por via de consequência, como é do Estado a tarefa de resolver todos os nossos 
problemas, compete a ele, e só a ele, a tarefa de julgar nossos litígios. (FIUZA, 1995, p. 217).

Quando o Judiciário atua, este processa um conflito social, mas não significa, necessariamente, que sane uma relação social. Este ato apenas encerra uma questão, mas não impede que outras tantas semelhantes apareçam posteriormente. Assim, ele funcionaliza os dissensos, mas não a própria vida. A paz do direito pode até vir a funcionar pela capacidade coercitiva da atividade jurisdicional, mas isto não significa que as partes estejam satisfeitas, nem que a essência do conflito tenha sido solucionada. Não pode restar ao direito o simples alívio de um sintoma, enquanto o verdadeiro mal ainda persistir.

José Luiz Bolzan de Morais e Fabiana Marion Spengler concluem:

(...) Para os operadores do direito, por um lado, as possibilidades propostas por mecanismos consensuais de reconstrução dos litígios permitem supor o evitar as deficiências profundas - instrumentais, pessoais, de custos, de tempo, etc. - próprios à "Grande Justiça" - a jurisdição estatal - marcando, apesar das insuficiências, inevitavelmente um reforço das relações de cidadania sendo privilegiado como instrumento apto a pôr fim a conflitos que se prolongariam, caso fossem levados à jurisdição estatal nos moldes tradicionais, mas, por outro, supõem, para muitos, a aceitação crítica desses métodos sem sequer considerar que essa temática necessita ser pensada em um quadro mais amplo no contexto dos projetos de reforma do Estado, em particular no que diz respeito ao que nominamos funções do Estado Contemporâneo - no qual a saga privatista aparece como o virtual paraíso suposto por um ética, quase religiosa, descompromissada (?) com os sofrimentos terrenos, transposta para o âmbito da economia, do direito e do Estado. (MORAIS; SPENGLER, 2008, p. 125).

Nesta esteira, pensar sobre uma campanha pela eficaz utilização dos métodos adequados de solução de conflitos pressupõe um duplo viés: por um lado, um interno, que aponta para seu contexto autonomizante, por outro, o aspecto externo, que reflete a responsabilidade com uma proposta de sociedade (neo)liberal. (MEIRELLES; MIRANDA NETTO, 2009).

A mediação, a conciliação, a negociação e a arbitragem estão elencadas dentre os meios adequados de solução de conflitos. É importante ressaltar que cada procedimento se encaixa melhor em determinada situação, não cabendo qualquer juízo de mérito a respeito de qual seria, genericamente, o melhor deles, o que justifica e explica a nomenclatura. 
No rol destes métodos adequados de solução de conflitos, destaca-se o instituto da mediação, que nas palavras de Marilene Marodin e John Haynes:

(...) é o processo no qual uma terceira pessoa - o mediador - auxilia os participantes na resolução de uma disputa. O acordo final trata o problema com uma proposta mutuamente aceitável e será estruturado de modo a manter a continuidade das relações das pessoas envolvidas no conflito. (HAYNES; MARODIN, 1996, p. 11).

Logo, não há parte vencedora ou parte perdedora. É composto um acordo pela flexibilização de ambas as partes, tendo o diálogo como instrumento facilitador, incitado pela figura do mediador.

É possível observar que o principal objetivo da mediação é o restabelecimento da comunicação entre as partes envolvidas, uma vez que esta, em meio a um conflito, fica prejudicada, tensa, acabando por aumentar a intensidade do mesmo. O papel do mediador é melhorar a capacidade de comunicação entre os mediandos na busca de uma solução conjunta para o problema. (OSTERMEYER, 1996).

A negociação consiste da forma elementar de resolução de controvérsias. Sem a necessidade da participação de terceiros, consiste da própria rotina transacional, onde a argumentação é a base do procedimento. Segundo Lília Maia de Morais Sales:

(...) A negociação é um procedimento muito comum na vida do ser humano. As pessoas estão sempre negociando a qualquer tempo e lugar. Uma criança negocia com outra um brinquedo ou um postal; um professor ajusta com o coordenador a sala de aula que irá ocupar; o cantor negocia o tipo de show que apresentará, enfim, antes da negociação ser um fato jurídico, ela é um acontecimento natural. (SALES, 2004, p. 36).

A conciliação é um meio de solução de conflitos que conta com o auxílio de um terceiro, denominado conciliador, o qual interfere no processo visando à obtenção de um acordo. Tal procedimento, em um primeiro momento pode causar certa confusão com a mediação, porém a diferença fundamental está na maneira como o diálogo é conduzido, com ou sem a interferência da terceira pessoa.

Como sua finalidade recai sobre a obtenção do acordo, a atuação do conciliador é mais interventiva que a do mediador, sendo permitida a sugestão de 
soluções juntamente às partes, tanto sobre as alternativas para o problema, quanto ao teor do acordo a ser firmado. (SALES, 2004, p. 39).

Por fim, na arbitragem, as partes escolhem livremente um árbitro, pessoa de confiança e especialista na controvérsia em questão, para decidir conflitos relativos a direitos patrimoniais disponíveis.

O processo de arbitragem se distingue da mediação e da conciliação pelo seu aspecto formal, com regras legais que condicionam sua validade, caso contrário o mesmo poderá ser declarado nulo. A decisão é irrecorrível em instâncias judiciais, e constitui título executivo judicial. Por fim, para Carlos Alberto Carmona:

(...) Pode-se definir confortavelmente arbitragem como um meio alternativo de solução de controvérsias através do qual as partes em litígio envolvendo direito disponível escolhem um juiz privado para decidir a controvérsia de forma autoritativa, ou seja, vinculativa para os litigantes. Querem os contendentes, ao escolher a via alternativa, prudente distância do Poder Judiciário (cujas decisões, via de regra, são seguras, porém muito morosas), procurando solução rápida, deformalizada e especializada para seus conflitos, aproveitando-se do sigilo propiciado pelo método em questão e da possibilidade de indicar como julgador um especialista na matéria objeto da disputa, eliminando-se, como é fácil perceber, muitos dos componentes aleatórios que podem levar à frustração da solução judicial das disputas. (CARMONA, 1999, p. 421).

Apesar do movimento global que abraça tanto a mediação como os outros métodos adequados de solução de conflitos, estes institutos têm encontrado certas limitações ao ingressar em nossas fronteiras, pois a solução que vem sendo proposta pelo Estado seria, ao invés de criar movimentos alternativos ao Judiciário estatal, conduzir reformas no processo a fim de que estes consensos sejam atingidos dentro do mesmo, ou seja, que a flexibilização pretendida ocorra dentro do próprio Judiciário.

O risco assumido ao enveredar por esse caminho é o de restringir a aplicação do instituto alternativo a somente um nicho do mercado, como aconteceu com a arbitragem. Esta, por questões culturais, teve sua utilização condicionada às relações empresariais, originalmente mais dependentes de uma ideologia global do que nacional, fatalmente optantes por abrir mão de um Judiciário lento, caro e imprevisível.

Quer parecer que o CNJ deseja recuar um pouco agora, para, posteriormente, obter um maior avanço. Como um exercício didático da própria 
cidadania, a mediação começaria a ser trabalhada dentro do Judiciário, para depois, aos poucos, ser entregue às mãos da própria sociedade civil organizada.

Tal hegemonia do Judiciário, no contexto da implementação da mediação, tem uma grande desvantagem. Elígio Resta, uma das maiores autoridades em mediação na Itália, tem uma atitude muito violenta em relação à mediação judicial. Segundo o professor, o procedimento, nesses moldes, nem poderia ser chamado de mediação, pois ao ser processualizada, a mediação seria contaminada pelos vícios do processo. São colocados argumentos no sentido de que o juiz deve ser equidistante das partes, já o mediador, equipróximo; é vedado escolher o juiz que irá julgar determinada causa, ao passo que o mediador é escolhido pelas próprias partes; o juiz, ao julgar determinada causa, só pode levar em consideração os fatos trazidos no próprio processo, enquanto a abrangência de conteúdo a ser abordado na mediação pode ir além dos limites do próprio processo, dentre outros pontos.

Não se deve pretender que a mediação seja a panacéia da solução dos conflitos, mas mais uma ferramenta nas mãos do juiz. A ideia contida no novo Código de Processo Civil é justamente a de um juiz gerenciador, um juiz que tenha em suas mãos instrumentos variados a se adequarem a diferentes conflitos.

E mais do que isso, segundo Warat, a jurisdição trabalha com a falsa ideia de que conflitos podem ser resolvidos. A maioria dos conflitos não pode ser resolvida, mas será monitorada e mantida dentro de determinados parâmetros de aceitabilidade social. Esta seria a verdadeira razão de ser da jurisdição, e para isso o juiz contaria com vários elementos, podendo utilizá-los dentro e fora do processo.

\section{MEDIAÇÃO: ODE À COMUNICAÇÃO}

A sociabilidade é condição inerente à própria essência humana. De acordo com Sartre ${ }^{4}$, os homens estão condenados a serem livres por não poderem abdicar de sua liberdade sem abrir mão de sua condição humana, lógica esta que se reflete no tocante à convivência com seus iguais.

\footnotetext{
${ }^{4}$ Jean-Paul Sartre (21 de Junho de 1905 -15 de Abril de 1980), filósofo existencialista francês do início do século XX.
} 
Decorrente da necessidade de conviver e de se envolver com o outro, também se mostra inevitável à realidade humana a existência dos conflitos (SERPA, 1999, p. 24), situações naturais das relações humanas, provocados por desgastes de relacionamentos, construção de interesses específicos, divergências de expectativas, dentre outros, sendo que a sociedade sempre buscou, de alguma maneira, resolver estes conflitos, seja da forma litigiosa ou consensual (ALVIM, 1996 apud MORAIS; SPENGLER, 2008, p. 113-114).

A implantação das práticas discursivas e narrativas da mediação convergem diretamente ao pensamento de Habermas, para quem "sob as condições de uma compreensão pós-metafísica do mundo, só tem legitimidade o direito que surge da formação discursiva da opinião e da vontade de cidadãos que possuem os mesmos direitos". Estes cidadãos, por sua vez, só poderão ter consciência de sua autonomia pública, na medida em que esteja assegurada sua autonomia privada. Neste sentido, "uma autonomia privada assegurada serve como garantia para a emergência da autonomia pública, do mesmo modo que uma percepção adequada da autonomia pública serve como garantia para a emergência da autonomia privada" (HABERMAS, 2003, p. 146).

Perseguindo este ideal de autonomia privada, o indivíduo se torna sujeito de suas relações, sejam elas conflituosas ou não, tornando-se interlocutor direto das mesmas. Daí Habermas, em sua Teoria do Agir Comunicativo, propõe uma estrutura dialógica, dando ao indivíduo condições de se orientar para um acordo, para o entendimento mútuo que leva ao consenso, permeado por um diálogo aberto, chamando especial atenção para o importante papel da linguagem na interação humana:

(...) no caso da ação comunicativa a linguagem se constitui num meio capaz de possibilitar inteiramente 0 entendimento mútuo. A linguagem se apresenta, então, como motor da integração social, tendo a comunicação como o veículo de construção de uma identidade comum entre indivíduos... aí reside a possibilidade de que os indivíduos em interação sejam capazes de discernir e fundamentar, com base em uma formação da vontade autônoma, as questões éticas e morais que se colocam a partir da vivência social. A verdade deixa de ser uma certeza absoluta e passa a ser um procedimento para se chegar a um acordo coletivo. A conseqüência imediata de um pensamento desenvolvido sobre estas bases é bem clara: a comunicação pode retornar ao âmbito da esfera pública, tornando-se seu princípio constitutivo central. (COUTINHO, 2005, p. 345). 
Há uma enorme simplicidade nas normas que comandam o agir comunicativo e o discurso de Habermas, que visa o entendimento mútuo. Elas fazem parte do bom senso do dia-a-dia, sempre que se busca o entendimento: a universalidade, o respeito pelo outro, a veracidade, a sinceridade e o respeito pela verdade que excluem qualquer artifício que possa distorcer o processo do diálogo e da busca pelo verdadeiro e o justo, e, finalmente, a renúncia a todas as formas de violência e coação. Em prol da integração social, e consequentemente, da democracia e da cidadania, possibilitariam a resolução dos conflitos vigentes na sociedade não com uma simples solução, mas com a melhor solução, resultado do consentimento de todos os concernidos.

A Ética do Discurso, graças a sua própria essência linguística-pragmática, implica intersubjetividade, capacidade de convivência, diálogo, busca de unidade na diversidade de posturas frente à existência. Não significa intentar uma unidade de convicções, mas buscar um mínimo racional capaz de permitir a produtiva convivência em sociedade, promovendo através da pluralidade de experiências, e do respeito mútuo, uma dinâmica mais rica do tecido social como um todo. (GUERRA FILHO, 2009, p. 169).

\section{Segundo Gilvan Hansen,}

(...) A ideia de uma sociedade melhor parece perpassar a própria história humana, mas ela é tão somente uma ideia que orienta a própria possibilidade da existência humana. A maneira com que cada época vai buscar construir uma sociedade melhor e os critérios que vão definir o que se entende por uma sociedade menos ameaçada - o conteúdo, em suma serão definidos no dia a dia da experiência comunicativa de cada época, por sujeitos reais vivendo situações específicas e tendo biografias peculiares, originais e únicas. (HANSEN, 1999, p. 144).

Cumpre ressaltar ainda que, o instituto da mediação, quando equivocadamente respaldado fora de sua verdadeira essência, pode vir a representar tão somente mais uma estratégia política, propagandista, ou mera demanda de mercado. Ao ser interpretado pela ótica de uma racionalidade instrumental como uma tentativa de trazer mais agilidade para as decisões judiciais e desafogar os operadores do direito, desvirtua-se de seu verdadeiro objetivo de ferramental favorável ao resgate das instâncias de deliberação intersubjetiva do mundo da vida e 
da promoção de uma cidadania eticamente balizada em procedimentos democráticos.

\section{QUEM, $O$ QUE E COMO MEDIAR?}

O mediador é aquela terceira pessoa imparcial escolhida ou aceita pelas partes, com o intuito de facilitar a comunicação, auxiliar o diálogo entre os envolvidos, diminuir a hostilidade, visando transformar o impasse apresentado e possibilitar que as próprias partes encontrem o caminho satisfatório para a solução do conflito.

O mediador deve ser capaz de ouvir e tranquilizar as partes, fazendo-as compreender que ele entende o problema; passar confiança às partes; explicitar sua imparcialidade; mostrar às partes que seus conceitos não podem ser absolutos; fazer com que as partes se coloquem uma no lugar da outra, entendendo o conflito por outro prisma; auxiliar na percepção de caminhos amigáveis para a solução do conflito; ajudar as partes a descobrir soluções alternativas, embora não deva sugerir o enfoque; compreender que, ainda que a mediação se faça em nome de um acordo, este não é o único objetivo (WARAT, 1999, p. 122-123).

E é neste contexto que emerge a importância de se fixar as habilidades que devem possuir estes profissionais, consideradas não somente necessárias como também indispensáveis para o exercício da função, incluindo os conhecimentos específicos, dependendo da matéria em discussão, e também importantes habilidades pessoais, onde destaca-se a capacidade de comunicação e a sensibilidade, como opina Warat, com total propriedade:

(...) O grande segredo da mediação, ao meu ver, como todo segredo é muito simples, tão simples que passa despercebido. Não digo que tentemos entendê-lo, pois não podemos entendê-lo. Muitas coisas em um conflito estão ocultas, mas podemos senti-las. Se tentarmos entendê-las, não encontraremos nada, e correremos o risco de agravar o problema. Para mediar, como para viver, é preciso sentir o sentimento. (WARAT, 2001).

De acordo com Jean Six, "são necessários perceber três componentes para a formação do mediador: a matéria-prima (homem), a teoria e a prática." (SIX, 2001, p. 271). Por matéria-prima se entende o homem, e o bom mediador entende que 
sua formação é contínua, justamente por estar o ser humano em contínuo desenvolvimento. A identidade do mediador é inventada constantemente, não se dá de uma vez por todas, é sempre afinada, trabalhada, atualizada. Em relação à teoria, é necessária uma boa fundamentação da mediação como instrumento democrático e sua adequação para os determinados tipos de conflitos. Finalmente, o estudo dos casos práticos e o trabalho com casos concretos possibilitam que o mediador saiba quando e como começar, quando continuar e quando encerrar uma mediação (SALES, 2010, p. 49).

O mediador, ainda, não pode calcar sua identidade na lógica binária, do "ou isto ou aquilo", tão difundida no mundo atual devido à propagação das ciências e da tecnologia, mas utilizar como ferramenta a percepção dialética, aquela que admite uma terceira possibilidade, sendo esta postura vantajosa por melhor condizer com a complexibilidade do real. Ainda de acordo com Six, nas palavras de Bolzan de Morais, neste ponto deve se engajar a luta do mediador:

(...) Olhar o "3", tarefa de todo o mediador, é perceber a terceira dimensão e valorizá-la ali onde se tem a tendência de aplainar o real e de mostrar o mundo e os seres em duas dimensões. Fazer o "3" é provocar as pessoas e situações para que elas não se deixem aprisionar no preto e branco, no maniqueísmo. Isso só se pode viver tendo o gosto pela complexidade: é a inteligência objetiva da complexidade do mundo, não a ignorância ou a inefabilidade, que pode hoje fundar novamente os símbolos no senso comum. (MORAIS; SPENGLER, 2008, p. 162).

No mesmo sentido, segundo Resta:

(...) dito em uma fórmula, enquanto o juiz é pensado, nos sistemas modernos, como o nec utrum, nem um nem outro, nem isto nem aquilo, justamente neutro, o mediador deve ser isto e aquilo, deve perder a neutralidade e perdê-la até o fim. Enquanto as partes litigam e só vêem seu ponto de vista, cada uma de maneira espetacular em relação à outra, o mediador pode ver as diferenças comuns aos conflitantes e recomeçar daqui, atuando com o objetivo de as partes retomarem a comunicação, exatamente o múnus comum a ambas. 0 mediador é agora meio para a pacificação, remédio para o conflito graças ao estar entre os conflitantes, nem mais acima, nem mais abaixo, mas no seu meio. (RESTA, 2004, p. 126).

Os conflitos provenientes das relações da família são um terreno riquíssimo para a atuação da prática da mediação, justamente pela preocupação com a preservação emocional das partes, e com o fato das relações serem continuadas no tempo, onde a mediação fornece às partes a capacidade de aprender a lidar com as 
emoções, tanto no tocante aos problemas quanto às soluções, construindo outras alternativas, e devolvendo às mesmas a capacidade e a oportunidade de retomar a posição de protagonistas de suas próprias decisões. Os mediadores não têm o intento de resolver conflitos, mas de permitir que as pessoas encontrem saídas para seus próprios conflitos.

Ao reconhecer e atuar no universo sentimental das crises envolvendo a família, o processo da mediação permite o reconhecimento, por meio das partes, de que as emoções são tanto parte do problema como de sua solução, e que uma vez encaradas e clareadas, facilitam a reorganização das funções, papéis e obrigações da família. Neste sentido, Águida Arruda Barbosa enfatiza:

(...) A mediação é uma estrutura que se apóia na dicotomia pensamento/sentimento, exigindo mudança de mentalidade para se valer desta prática, pressupondo estudos que contemplam o entendimento da essência da efetiva demanda jurisdicional, que vem a ser o reconhecimento do valor maior da vida em sociedade - a cidadania - que promove a inserção do homem enquanto ser social, porém, a inovação a ser agregada é a consciência de que o humano é, sobretudo, um ser afetivo. (BARBOSA, 2004, p. 387).

Ainda nessa esteira, nas palavras de Carreira Alvim:

(...) o direito só se transforma em justiça quando passa pela alma, pelo sentimento de quem julga. A lei, dizia São Tomás de Aquino, "padece do pecado original", que é ser uma "regra geral a aplicar-se a casos particulares". É uma roupa que não serve em todos os corpos, a não ser que haja um "costureiro habilidoso", para fazer com que ela sirva, tanto nas pessoas grandes, como nas pequenas; tanto nos ricos como nos pobres. Aí teremos, então, justiça. E é por isso que justiça não é privilégio de juiz togado. Aliás, a verdadeira justiça é aquela feita com base nos princípios da equidade; aquela que é feita para cada caso; aquela que, ainda que moldada na lei, atende às circunstâncias peculiares, específicas, de cada caso concreto. (ALVIM, 2003).

\section{CONSIDERAÇÕES FINAIS}

À guisa de conclusão, o grande desafio a ser proposto segue no intento de promover uma mudança de paradigma acerca do limite da interferência estatal no universo dos conflitos humanos, estimulando um alargamento da consciência das partes e dos próprios operadores do Direito, no sentido de permitir e incentivar a prática da mediação dentro dos moldes de proteção que uma Constituição garantista deve ser capaz de exercer, tornando-se verdadeiramente equivalente ao processo 
judicial enquanto forma legítima de solução de conflitos no Estado Democrático de Direito.

A proposta apresentada pela mediação converge no sentido da teoria habermasiana, como meio hábil que possibilita a emancipação do indivíduo e da comunidade na qual se insere, insurgindo nos sujeitos a responsabilidade pela solução de suas próprias demandas, fortalecendo seus princípios de cidadania, bem como, ao propor o deslocamento do paradigma da relação adversarial para uma relação dialógica, ruma ao objetivo primordial da pacificação social.

É preciso forçar uma conscientização a favor da responsabilidade de fazer o direito e os remédios legais refletirem a real necessidade da sociedade e do atual momento histórico, efetivando-se o dever de encontrar alternativas que respondam às demandas sociais. Nesta lógica, os mecanismos da oralidade, informalismo e conciliação, presentes na mediação, se coadunam fazendo frente à concretização de novos direitos, aproximando a Justiça de seus demandantes, permitindo o exerć́cio pleno da cidadania.

\section{REFERÊNCIAS}

ALVIM, José Eduardo Carreira. Alternativas para uma maior eficácia da prestação jurisdicional. Revista de Processo, São Paulo, v. 21, n. 84, p. 175-199, 1996.

ALVIM, José Eduardo Carreira. Arbitragem e o poder judiciário: convergências e divergências. In: SEMINÁRIO INTERNACIONAL SOBRE DIREITO ARBITRAL, 1., 2003, Belo Horizonte. Anais [...]. Belo Horizonte: Câmara de Arbitragem de Minas Gerais, 2003.

BARBOSA. Águida Arruda. Mediação familiar: instrumento para a reforma do judiciário. In: PEREIRA, Rodrigo da Cunha (coord.). Afeto, ética, família e o novo código civil brasileiro: anais do IV Congresso Brasileiro de Direito de Família. Belo Horizonte: Del Rey, 2004.

CAPPELLETTI, Mauro; GARTH, Bryant. Acesso à justiça. Tradução: Ellen Gracie Northfleet. Porto Alegre: S. A. Fabris, 2002.

CARMONA, Carlos Alberto. Árbitros e juízes: guerra ou paz? In: CARMONA, Carlos Alberto; LEMES, Selma M. Ferreira; MARTINS, Pedro A. Batista. Aspectos

fundamentais da lei de arbitragem. Rio de Janeiro: Forense. 1999. 
CARVALHO, José Murilo de. Cidadania no Brasil, o longo caminho. 3. ed. Rio de Janeiro: Civilização Brasileira, 2002.

COUTINHO, Sérgio. A recepção como "pragmática argumentativa" uma visita ao conceito pelo olhar habermasiano. Perspectiva Teleológica, Belo Horizonte, v. 37, n. 103, p. 337-366, 2005.

FIUZA, César. Teoria geral da arbitragem. Belo Horizonte: Del Rey, 1995.

FUX, Luiz; BATISTA, Weber Martins. Juizados especiais cíveis e criminais e suspensão condicional do processo penal. Rio de Janeiro: Forense, 1999.

GARAPON, Antoine. O juiz e a democracia. Rio de Janeiro: Revan, 2001.

GUERRA FILHO, Willis Santiago. Teoria da ciência jurídica. 2. ed. São Paulo: Saraiva, 2009. v. 1.

HABERMAS, Jürgen. Direito e democracia: entre facticidade e validade. 2. ed. Rio de Janeiro: Tempo Brasileiro, 2003. v. 2.

HANSEN, Gilvan Luiz. Modernidade, utopia e trabalho. Londrina: CEFIL, 1999.

HAYNES, John M.; MARODIN, Marilene. Fundamentos da mediação familiar. Tradução: ASSUMPÇÃO, Eni; MARODIN, Fabrizio Almeida. Porto Alegre: Artes Médicas, 1996.

JUNQUEIRA, Eliane Botelho. Acesso à justiça: um olhar retrospectivo. Revista Estudos Históricos, Rio de Janeiro, v. 9, n. 18, p. 389-402, 1996.

MAMEDE, Gladston. A advocacia e a ordem dos advogados do Brasil. Porto Alegre: Síntese, 1999.

MARINONI, Luiz Guilherme. Novas linhas do processo civil. 4. ed. São Paulo: Malheiros, 2000.

MARSHALL, T. H. Cidadania e classes sociais. Rio de Janeiro: Zahar, 1967.

MEIRELLES, Delton Ricardo Soares; MIRANDA NETTO, Fernando Gama de. Meios alternativos de resolução de conflitos envolvendo a administração pública. In: ENCONTRO NACIONAL DO CONPEDI, 18., 2009, Maringá. Anais [...]. Maringá: Fundação Boiteux, 2009. p. 6385-6417. Disponível em: www.conpedi.org.br/anais/36/03_1320.pdf. Acesso em: 01 fev. 2020.

MORAIS, José Luiz Bolzan de. Crise(s) da jurisdição e acesso à justiça: uma questão recorrente. In: SALES, Lilia Maia de Morais (Org.). Estudos sobre mediação e arbitragem. Fortaleza: ABC Editora, 2003. 
MORAIS, José Luiz Bolzan de; SPENGLER, Fabiana Marion. Mediação e arbitragem: alternativas à jurisdição. 2. ed. Porto Alegre: Livraria do Advogado, 2008.

OSTERMEYER, Melinda. Realizar la mediación. In: DUFFY, Karen Grover; GROSCH, James W.; OLCZAC, Paul V. La mediación y sus contextos de aplicación: una introducción para profesionales e investigadores. Buenos Aires: Paidós, 1996.

RENAULT, Luiz Otávio Linhares. Das comissões de conciliação prévia: entre a penumbra e a luz. In: RENAULT, Luiz Otávio Linhares; Viana, Márcio Túlio (coord.). Comissões de conciliação prévia: quando o direito enfrenta a realidade. São Paulo: LTr, 2003.

RESTA, Eligio. O direito fraterno. Santa Cruz do Sul: Edunisc, 2004.

ROTH, André-Noel. O direito em crise: fim do estado moderno? In: FARIA, José Eduardo. Globalização econômica: implicações e perspectivas. São Paulo: Malheiros, 1996.

SALES, Lília Maia de Morais. Justiça e mediação de conflitos. Belo Horizonte: Del Rey, 2004.

SALES, Lilia Maia de Moraes. Mediare: guia prático para mediadores. 3. ed. Rio de Janeiro: GZ Editora, 2010.

SANTOS, Boaventura de Sousa. Para uma revolução democrática da justiça. 3. ed. São Paulo: Cortez, 2011.

SERPA, Maria de Nazareth. Teoria e prática da mediação de conflitos. Rio de Janeiro: Lumen Juris, 1999.

SIX, Jean-François. Dinâmica da mediação. Belo Horizonte: Del Rey, 2001.

VIANNA, Luiz Werneck; CARVALHO, Maria Alice Resende; MELO, Manuel Palacios Cunha; BURGOS, Marcelo Baumann. A judicialização da política e das relações sociais no Brasil. Rio de Janeiro: Revan, 1999.

WARAT, Luis Alberto. 0 ofício do mediador. Florianópolis: Habitus, 2001.

WARAT, Valéria. Mediação e psicopedagogia: um caminho para construir. In: WARAT, Luiz Alberto (Org.). Em nome do acordo: a mediação no direito. 2. ed. Argentina: Almed, 1999. 
WATANABE, Kazuo. A mentalidade e os meios alternativos de solução de conflitos. In: GRINOVER, Ada Pellegrini; WATANABE, Kazuo; LAGRASTA NETO, Caetano. Mediação e gerenciamento do processo. São Paulo: Atlas, 2007.

Recebido em 13/02/2020.

Aceito em 28/02/2020. 